\title{
DESENVOLVIMENTO TERRITORIAL SUSTENTÁVEL EM DEBATE: ESTRUTURA E ORGANIZAÇÃO DA PESCA ARTESANAL NA GRANDE FLORIANÓPOLIS
}

\author{
Elaine Cristina de Oliveira Menezes' \\ Maurício Serva²
}

\begin{abstract}
Resumo
O presente estudo tem como objetivo identificar as principais características da pesca artesanal da Grande Florianópolis, sua estrutura e organização, buscando avaliar a sua potencialidade na promoção de dinâmicas locais de desenvolvimento sustentável. Apresentamos como conceito norteador o Desenvolvimento Territorial Sustentável, reforçado pela definição de Governança e de Economia Social e Plural. A pesquisa é predominantemente qualitativa, valendo-se de entrevistas semi-estruturadas. Os resultados demonstram que as comunidades de pesca estão procurando alternativas e, principalmente, estão buscando fortalecer a governança local do setor. No entanto, percebemos limites dessa governança, especialmente em relação a presença de uma cultura política clientelista e paternalista. Observamos a necessidade de investimento, por parte da gestão pública, não só em equipamentos e petrechos de pesca, mas em aprendizagem coletiva.
\end{abstract}

Palavras-chave: Desenvolvimento territorial sustentável. Governança. Pesca artesanal.

Classificação JEL: Q56.

CIRIEC-Brasil. E-mail: eoliveira.menezes@gmail.com. Fone: 04884077709

Universidade Federal de Santa Catarina. E-mail: mauserva@gmail.com. Fone: 04837219374 


\section{INTRODUÇÃO}

$\mathrm{Na}$ atualidade observamos que o aumento da produtividade gerada pelas inovações tecnológicas tem sido acompanhado por uma constante concentração da riqueza e da renda, resultando em crescentes desigualdades sociais, miséria e exclusão. Do ponto de vista socioambiental, percebemos o avanço de inúmeros problemas acarretado pelo uso desordenado dos recursos naturais. Em meio a esse contexto verificamos, também, o surgimento de novas formas de organização social e de inserção no mercado e uma crescente discussão sobre os limites do crescimento econômico e da capacidade de suporte dos ecossistemas.

Como enfrentamento dessas dificuldades, especialmente da crise do emprego, observamos que a emergência das organizações sociais se coloca como alternativa e fonte de renda para uma parcela da população que está recorrentemente excluída do mercado formal de trabalho (ONETO, 2005). Essa nova prática organizacional é considerada, por inúmeros estudiosos, uma forma avançada de gestão democrática e participativa, compatível com uma perspectiva do desenvolvimento mais equilibrado. Esse novo estilo de desenvolvimento, a nosso ver, formatado no âmbito do desenvolvimento territorial sustentável, apóia-se nos pressupostos do ecodesenvolvimento e na abordagem do desenvolvimento territorial, buscando enfatizar a importância de se compreender as várias dimensões do desenvolvimento para obtenção do que entendemos ser relevante na atualidade, a qualidade de vida e, consequentemente, a qualidade territorial.

A problemática de cunho mais geral descrita anteriormente tem reflexos no âmbito setorial, especialmente em setores tradicionais, como é o caso da pesca artesanal. No Brasil, no que se refere a pesca artesanal observamos, através da iniciativa do Governo Federal com a instituição do Ministério da Pesca e a fundação da Secretaria Especial de Aqüicultura e Pesca da Presidência da República, em 2003, a criação de expectativas para o avanço da atividade. Embora haja toda uma discussão sobre a evolução desse segmento no Brasil, constata-se que a pesca artesanal, que possui grande relevância socioeconômica no litoral de Santa Catarina, empregando cerca de 25 mil pescadores artesanais, vêm sofrendo com a concorrência dos barcos de pesca (economicamente mais eficazes na pesca de alto-mar), tornando os pescadores assalariados e com a introdução de uma infra-estrutura turística, 
Desenvolvimento territorial sustentável em debate: estrutura e organização da pesca artesanal na Grande Florianópolis

em que as famílias desses pescadores foram sendo absorvidas parcialmente nas funções subalternas de escala ocupacional (nos setores de hospedagem e alimentação) (SEVERO, 2008;OURIQUES, 2007).

O próprio processo de urbanização desordenado do litoral catarinense e a degradação ambiental vêm trazendo inúmeros malefícios à vida sustentável dos pescadores e da própria pesca artesanal, principalmente na região da Grande Florianópolis. Nessa região o trabalho na atividade turística vem tornando-se forte concorrente, especialmente junto aos filhos de pescadores artesanais. A partir do quadro de pressões sofrido pela pesca artesanal na atualidade observamos que essa atividade requer um olhar atencioso, tanto por parte da gestão pública, quanto por parte dos próprios atores sociais que a compõe.

Assim, este artigo tem por objetivo, analisar e identificar as principais características da pesca artesanal da Grande Florianópolis, sua estrutura e organização, buscando avaliar a sua potencialidade na promoção de dinâmicas locais de desenvolvimento mais sustentáveis, social e ambientalmente. Para tanto, este artigo propõe-se, num primeiro momento, caracterizar a atividade da pesca artesanal, a partir das mudanças socioeconômicas, da degradação ambiental e do significativo aumento populacional (desordenado) ocorrido nas últimas décadas na região. Num segundo momento, busca avaliar a estrutura dos arranjos institucionais, seja no âmbito da gestão pública, do mercado e da sociedade civil organizada, identificando os principais atores-chave. Por fim, faremos um balanço das potencialidades e dos limites, especialmente no que se refere à sustentabilidade socioambiental, dessa atividade tradicional na Grande Florianópolis.

\section{ASPECTOS METODOLÓGICOS}

O presente estudo é do tipo empírico, valendo-se de um arcabouço teórico para norteá-lo. Caracteriza-se, também, como um estudo exploratório-descritivo. Exploratório porque pretende não apenas configurar e diagnosticar o estágio atual da pesca artesanal na Grande Florianópolis, mas também avaliar os arranjos institucionais que estão interferindo e contribuindo para a organização do setor. E é descritivo, pois de acordo com Triviños (1987), pretende descrever as características do fenômeno, em especial, apontando para o quadro estatístico da pesca, identificando a estrutura e as características do segmento de pesca artesanal na região. 
A pesquisa valeu-se, também, de uma abordagem qualitativa, visto que, privilegia a interpretação da percepção dos sujeitos de pesquisa. Nesse sentido, possibilitou uma análise mais profunda do tema, sendo este tipo de abordagem mais compatível com a perspectiva teórica adotada neste artigo, fundamentada no DTS, governança e economia social, que concebem os eventos socioeconômicos como sendo também eventos socioambientais. Além de que essa abordagem é mais compatível com a técnica de coleta de dados que foi adotada nesse estudo, a entrevista semi-estruturada.

O universo da pesquisa recobre a região da Grande Florianópolis. Porém, procuramos identificar os municípios cuja pesca artesanal tivesse maior representatividade. Dentre os 22 municípios, selecionamos, por meio dos dados da RAIS (2010) e de entrevistas exploratórias, Florianópolis e Governador Celso Ramos, em função da sua representatividade no número de empregos gerados. Quanto aos participantes da pesquisa foram representantes de instituições públicas e entidades de classe, especialistas relacionados ao segmento de pesca artesanal, membros das comunidades pesqueiras e de associações do segmento da região em foco. O levantamento de informações também incluiu fontes de dados primários e secundários. Os dados primários foram obtidos, na pesquisa de campo, através da aplicação de entrevistas semi-estruturadas, como destacado anteriormente. Além da técnica de entrevista semi-estruturada, utilizamos também a técnica de coleta chamada "observação", pois possibilita a obtenção das informações no momento em que elas ocorrem ${ }^{3}$. Os dados secundários foram obtidos através de pesquisa documental e dados levantados em periódicos, revistas, jornais e demais publicações da região.

A interpretação dos dados foi desenvolvida de acordo com a análise qualitativa e descritiva do conteúdo, correlacionando-se com o referencial teórico assumido. Através das entrevistas aplicadas, bem como, a observação realizada no estudo de campo, foi possível realizar a triangulação dos dados obtidos para que a análise e interpretação dos dados fossem realizadas de forma confiável (TRIVIÑOS, 1987). Para dar suporte a coleta e análise dos dados, elaboramos uma matriz teórico-metodológica, cujos principais conceitos foram o do desenvolvimento territorial sustentável, governança e economia social e plural. A seção seguinte apresenta uma discussão sobre os conceitos adotados nessa matriz teórico-metodológica.

Essas serão complementadas com o uso de "Diário de Campo" que auxilia no registro dos fatos observados. 
Desenvolvimento territorial sustentável em debate: estrutura e organização da pesca artesanal na Grande Florianópolis

\section{DESENVOLVIMENTO TERRITORIAL SUSTENTÁVEL: CONTRIBUIÇÕES DOS ESTUDOS SOBRE GOVERNANÇA TERRITORIAL E ECONOMIA SOCIAL E PLURAL}

A problemática socioambiental emergiu no campo do planejamento do desenvolvimento no final dos anos 1960 e, inicialmente, no âmbito restrito dos países industrializados. Sua agenda de prioridades contemplava os problemas da contaminação e degradação ambiental e do esgotamento dos recursos naturais, agravado pelo acelerado crescimento demográfico. $\mathrm{Na}$ década seguinte, o foco começou a se deslocar no sentido da incorporação das assimetrias Norte-Sul e do fenômeno da "poluição da pobreza" (SACHS, 2007). Atualmente o critério de sustentabilidade ampliada, que articula as dimensões socioeconômica, sociocultural, sociopolítica e socioecológica vem se impondo como um fator determinante no desenho de estratégias alternativas de desenvolvimento rural e urbano.

Dentre os primeiros acontecimentos relevantes em âmbito internacional que levantaram o debate sobre meio ambiente tem-se o Relatório de Founex que apontou os principais tópicos relacionados aos problemas do meio ambiente, rejeitando as abordagens reducionistas do ecologismo "a qualquer preço" e do economicismo estreito (SACHS, 1993). Esses debates foram uma preparação para a Conferência das Nações Unidas que seria realizada, em 1972, em Estocolmo e que buscava, de acordo com Sachs (1992), uma via intermediária entre as duas visões radicais apontadas acima. Para Sachs (1992, p. 07) "a lição mais proveitosa que surgiu de Founex, e depois de Estocolmo, é que seria possível imaginar um caminho de desenvolvimento que fosse ao mesmo tempo socialmente útil, ecologicamente prudente e que atendesse a critérios de eficiência econômica".

Posteriormente, o tema fortaleceu-se com a realização do Seminário do México, em 1974, com a publicação do Relatório Brundtland em 1987, e da realização da Conferência do Rio de Janeiro, ECO 92. Esses eventos e documentos produzidos entre 1970 e 1980 conduziram a progressos conceituais, ampliando conhecimento empírico sobre o funcionamento da biosfera, sobre os riscos das atividades humanas, além do avanço na institucionalização da preocupação com o planejamento e gestão ambiental (SACHS, 1993). Todavia, esse avanço não conseguiu promover uma tomada de consciência efetiva da crise socioambiental e dos seus reflexos no âmbito 
do mercado, incorporando a análise da qualidade do crescimento, com seus efeitos sociais, culturais e ecológicos.

Anexada a esta discussão surgem inovações teóricas e experiências no campo de estudo sobre desenvolvimento territorial, que teve como modelo a exitosa experiência da Terceira Itália. Nela se reconheceu a importância da dimensão territorial do desenvolvimento, cujas proximidades geográfica, cultural e organizacional existentes entre os agentes econômicos proporcionaram um tecido social propício a esse tipo de dinâmica produtiva. Por centrar força nas relações de reciprocidade e na solidariedade como opção de desenvolvimento, a Terceira Itália ofereceu um modelo antagônico àquele representado pelo Keynesianismo/Fordismo.

E é fundamentado nesses avanços teóricos que surge o conceito de Desenvolvimento Territorial Sustentável (DTS). Uma tentativa de acoplar aspectos do desenvolvimento territorial ao ecodesenvolvimento, obtendo como resultado da relação entre esses enfoques teóricos um novo enfoque, o do desenvolvimento territorial sustentável (VIEIRA e CAZELLA, 2004; VIEIRA, 2006). Essa abordagem leva em conta os aspectos territoriais, especialmente, as questões culturais, sociais e naturais locais, somado a busca da preservação do meio socioambiental no nível territorial (local). Por isso, consideramos fértil o aprofundamento das orientações teóricas sobre governança e economia social para compreender as dinâmicas territoriais e setoriais, embutindo nelas a perspectiva da sustentabilidade ambiental, como é o caso da pesca artesanal, apresentado na discussão da seção seguinte.

\subsection{Governança e economia social e plural no contexto do DTS}

As primeiras acepções do termo governança têm origem na França do século XIII (GAUDIN, 2002). Esse termo apresenta, porém, novos usos no transcurso do século XX. ${ }^{4}$ Além das referências ao domínio público, outros atributos reforçam a sua popularização, como é o caso da microeconomia. No contexto das bases analíticas da microeconomia e na busca de uma definição do conceito de governança, Gaudin (2002) divide-o em dois grandes eixos: um que enfatiza a governança interna das organizações,

\footnotetext{
Nos anos de 1990, conforme Gaudin (2002), descobre-se um poder não somente multipolar, complexo, fluído, mas também que é atualmente de alguma forma 'descentralizado'. O Estado não é mais o centro das coisas, depara-se na atualidade com um mundo no qual as instituições se estabelecem por um novo tripé: as relações internacionais, as regulações essenciais e os benefícios dos poderes locais.
} 
Desenvolvimento territorial sustentável em debate: estrutura e organização da pesca artesanal na Grande Florianópolis

seus sistemas de gestão e hierarquia; e outro que dá ênfase à governança territorial, cuja centralidade recai nos padrões de regulação institucional e de interação existentes no âmbito de um mesmo território.

Na perspectiva territorial, aplicada ao sistema socioeconômico, governança significa, então, um conjunto de sistemas de regulação intencional gerado por uma determinada organização social (BOURQUE, 2000). Para precisar essa definição, Bourque (2000, p. 10) adota o conceito de Hollingsworth e destaca que “ [...] un système de gouvernance est donc defini comme la totalité des arrangements institucionnels [...] qui régulent les transactions à l'intérieur et à travers les frontières d'un système économique. ${ }^{5}$."

Nesse sentido, observamos que a visão territorial da governança tem uma concepção mais ampla daquela que se tinha no século XIII e XIV e também uma concepção oposta à da governança mundial. Nessa perspectiva, a governança é mantida por um conjunto de atores e instituições que não pertencem somente à esfera governamental, mas que se traduzem pelas relações de interdependência existentes entre o poder e as instituições associadas a uma ação coletiva específica. A governança é um processo institucional e organizacional de construção de mecanismos compatíveis com os diferentes modos de coordenação existentes entre atores sociais geograficamente próximos, para que possam resolver os problemas produtivos inéditos, sentidos no território (PECQUEUR, 2004), e para solucionarem problemas que transcendem os limites das relações econômicas.

É preciso destacar a existência de um amplo espectro de tipos de governança na literatura acadêmica atual. Pesquisadores reconhecidos do tema, Benko e Lipietz (2000), destacaram que, no campo socioeconômico e numa acepção restrita, a governança pode ser também entendida como uma forma de organização inter-empresarial que se caracteriza por relações de poder que vão além do foco do mercado. Na concepção de Benko e Lipietz apud Courlet e Soulage (1994), a governança nos remete às formas intermediárias de regulação, sejam elas, mercantil ou estatal, e que articulam interesses privado e público, aspectos econômicos e sociais, declarando-se sensíveis aos critérios de eficácia e eqüidade. Essa é a visão clássica do termo governança no âmbito territorial. Porém, a concepção de Bourque

Tradução: "[...] um sistema de governança é então definido como a totalidade dos arranjos institucionais que regulam as transações no interior e através das fronteiras de um sistema econômico". 
(2000), cuja sistematização absorveu inúmeras formas possíveis de governança parece mais coerentes para projetos que estejam inseridos em uma perspectiva sistêmica do desenvolvimento e que contemple fortemente a dimensão sociopolítica desse desenvolvimento, cuja tipologia recobre os tipos: governança mercantil; governança hieráquica/corporativa; governança estatal; governança comunitária; e governança em parceria ${ }^{6}$.

A evolução desse debate reforça a impressão de que a experimentação com novas modalidades de ação coletiva, norteadas pelo ideário do desenvolvimento territorial, vem se intensificando nos últimos tempos. Como parte da ação conjunta tem-se a consolidação de relações de cooperação, reciprocidade e confiança que são promovidas principalmente pela proximidade geográfica e sociocultural (PECQUEUR, 2005). Além disso, consideramos fértil a análise pautada nos modos de coordenação, principalmente para compreender as novas formas de organização que emergiram nas últimas décadas. Num contexto de globalização assimétrica, essas novas modalidades de ação coletiva nos parecem, todavia, ainda fortemente condicionadas pela ideologia economicista, pois colocam em segundo plano o enfrentamento dos dilemas apontados pela visão ecológica dos limites do crescimento material. Por isso, se as atividades econômicas conseguirem se estruturar privilegiando modos de governança pautados em parcerias, baseados na consertação e na busca por equilíbrio entre as dimensões econômicas, sociais, políticas e ambientais, menos recorrentes seriam os impactos socioambientais graves.

\footnotetext{
Tipos de governança de Bourque (2000): i) governança mercantil: conjunto de mecanismos em que os agentes trocam os direitos de propriedade e mecanismos que repousam sobre regras universais: as relações são impessoais, as trocas permutáveis/intercambiáveis e os termos de troca devem satisfazer cada uma das partes; ii) governança hierárquica/ corporativa: coordenação exercida por uma autoridade hierárquica fundada sobre os direitos de propriedade, esses direitos de propriedade são definidos de uma maneira tal que as grandes gestoras passam a ser os macro-atores tratados como representantes legítimos de múltiplos acionistas; iii) governança estatal: papel de garantir o funcionamento apropriado dos outros modos de coordenação imposta ao conjunto de atores e das orientações, de acordo com a opinião pública, podendo contar com o potencial da força legítima para produzir bens públicos ou agir diretamente na produção de bens e serviços privados (a diversidade entre os países ou entre os setores econômicos constitui a mais importante fonte de variados sistemas nacionais de governança); iv) governança comunitária: coordenação das atividades ligadas aos indivíduos ou as organizações sobre a base de uma confiança mútua, esta apóia-se sobre relações pautadas em um conjunto de obrigações mútuas e as redes informais não são uma estrutura hierárquica formal e não desembocam sobre uma integração vertical; é um tipo de governança mais flexível que a governança hierárquica e mais estável que a mercantil; v) e, governança em parceria/associativa: contrariamente às redes informais da governança comunitária, as redes da governança associativa são mais formalmente institucionalizadas, constituindose o prolongamento formal da governança comunitária; também, por diversas razões (intermediação dos grupos de interesse, forte institucionalização, definição do bem público), a governança associativa é estritamente associada à governança estatal através das diversas formas de delegação de poder.
} 
Desenvolvimento territorial sustentável em debate: estrutura e organização da pesca artesanal na Grande Florianópolis

Essa percepção também é compartilhada na avaliação da governança dos recursos de uso comum, tendo como ponto referencial a obra de Ostrom (1990; 2010). A autora supramencionada identificou em seu estudo, em 1990, em Governing the Commons, que o funcionamento da ação coletiva não segue as hipóteses habituais da economia clássica. Ostrom (1990) enfatiza a importância da cooperação e da reciprocidade e para ela, não haveria cooperação sem reciprocidade. Assim, os atores se esforçam para identificar outros atores envolvidos e os consideram como possíveis cooperadores (SABOURIN, 2010). "Ostrom considera que a reputação constitui uma dessas informações que motivam a confiança no outro e, portanto, a reciprocidade na cooperação (SABOURIN, 2010, P. 4).

Dessa forma, Ostrom ao analisar dinâmicas produtivas comunitárias observou a importância de elementos que já foram enfatizados pelos teóricos do desenvolvimento territorial. Dentro desse espectro analítico Sabourin (2010) corrobora com a idéia de Ostrom de que as políticas sejam adaptadas em função da proporção ou da densidade de indivíduos « reciprocitários " ou egoístas. Tais contribuições teóricas nos permitem identificar a potencialidade de mecanismos de intensificação das relações entre os atores sociais, principalmente aqueles que estão mais excluídos da proliferação das inovações tecnológicas, da competitividade e do processo de globalização, como são os casos de organizações de economia social.

É no contexto de exclusão anteriormente descrito que observamos a relevância de se compreender as formas de organização social vinculadas à economia social. É preciso destacar que a emergência de novas formas de organização social vinculadas à economia social compôs o quadro de enfrentamento das transformações operadas no modelo de produção fordista. Conforme Lévésque (2007), o ambiente estudado pela economia social começa a se institucionalizar quando no final do século XIX observa-se a afirmação extrema do laissez-faire, cujos fenômenos marcantes foram: i) a autoproclamação da economia política como ciência; ii) o processo de internacionalização "imperialista"; iii) a organização científica do trabalho que acarreta o desaparecimento de algumas profissões e a desqualificação da massa trabalhadora.

Já no século XX, há uma crise que acompanha o desmoronamento progressivo dos governos comunistas que conforme exposto por Lévesque (2007, p. 50), tornaria “[...] possível a proposta neoliberal de uma auto- 
regulação pelo mercado". É essa conjuntura mundial que faz emergir o campo teórico da economia social. A abordagem da economia social, que tem grande contribuição de Laville, Eme e Roustang, promove um questionamento da relação economia/sociedade e do próprio fordismo, "principalmente o fato de que o desemprego se faz acompanhar paradoxalmente por um crescimento das necessidades não satisfeitas" (LEVÉSQUE, 2007, p. 52). As contribuições dos trabalhos dessa corrente teórica da Nova Sociologia Econômica - NSE foram destacados por Levésque (2007), sendo: uma análise da relação economia/sociedade e uma análise das experiências empreendidas na economia solidária.

Segundo Levésque (2007) a grande diferença entre a economia formal ortodoxa e a economia social está em definir a economia do ponto de vista substantivo, ou seja, incluem-se, além das práticas mercantis, aquelas não mercantis (a redistribuição) e não monetárias (a reciprocidade). “As iniciativas da economia solidária provêm de um engajamento cidadão que visa ampliar a democracia e promover a eqüidade" (LEVÉSQUE, 2007, p. 52). Tais características aproximam-se da concepção levantada pelos teóricos que estudam os modos de coordenação e governança e o desenvolvimento territorial sustentável (VIEIRA e CAZELLA, 2004; VIEIRA, 2006; BOURQUE, 2000). Por isso, neste artigo, buscamos fazer uma aproximação dessas correntes teóricas, que a nossa ver, são convergentes e completares entre si.

Enfim, a definição da economia social e solidária compartilha vários elementos com a definição do desenvolvimento sustentável, principalmente no que tange à eqüidade, à predominância das pessoas sobre o capital, ao domínio das comunidades sobre o seu próprio destino, etc. A internalização da oferta e da demanda pelas empresas, além de uma definição ampla da economia para incluir diversas formas de atividade, poderiam se revelar muito pertinentes para a construção de uma socioeconomia de desenvolvimento sustentável (LEVÉSQUE, 2007, P.53).

As palavras de Lévesque (2007), ao definirem o campo da economia social denotam a necessidade de integrarmos tais temas a compreensão de um novo estilo de desenvolvimento. Portanto, compreendemos que a economia social, baseada nos pressupostos apresentados acima, estuda formas socioeconômicas de natureza associativa, cujas premissas estão pautadas na 
Desenvolvimento territorial sustentável em debate: estrutura e organização da pesca artesanal na Grande Florianópolis

solidariedade e na democracia, primando os indivíduos e o trabalho, mais do que o capital na distribuição dos seus benefícios. Essas organizações de economia social têm por fim a solidariedade, a cooperação, a autogestão democrática em favor de quem as utiliza e, ainda, a eliminação do intermediário e a condução do capital com finalidade social (IRION, 1997).

Portanto, conforme avalia Lisboa (2002, p. 132) “a economia solidária aponta um caminho para construir uma economia reintegrada na sociedade e na biosfera, voltada para a provisão da vida das pessoas, possibilitando superar o corrosivo economicismo da vida moderna". Também, busca a conciliação entre o desenvolvimento econômico e social e a preservação da diversidade ambiental. Dessa maneira, Lisboa (2002) corrobora com Lévesque (2007) no que refere às contribuições desse tipo de organização social rumo a um novo estilo de desenvolvimento, aqui definido como o desenvolvimento territorial sustentável.

A economia social se caracteriza como sendo uma atividade baseada na associação de pessoas em entidades democráticas e participativas "[...] cuja ética baseia-se nos princípios de maximizar os benefícios de prestação de serviços para a comunidade, gestão autônoma e independente com processo de decisão democráticos e distribuição de resultados na proporção do trabalho e não do capital" (ONETO, 2005, p. 338). Esse novo campo de estudo, no Brasil, ainda não apresenta uma visão dominante, tanto na sua práxis, quanto no meio acadêmico. No âmbito da práxis, há uma ampla gama de atores e formas jurídicas. Enquanto que no meio acadêmico percebe-se a coabitação de inúmeras percepções desse conceito (SERVA; ANDION, 2005). As formas da economia social no Brasil que apresentam maior tradição são as cooperativas, incentivadas pela regulamentação da Lei 5.764, da criação do Conselho Nacional de Cooperativas. Por isso, consideramos férteis estudos sobre essas dinâmicas produtivas alternativas no Brasil e em Santa Catarina.

Em síntese, verificamos que a economia social, governança e o Desenvolvimento Territorial Sustentável são regidos por princípios que se complementam. Vemos na economia social a proposta de se criar um sistema social que garanta emprego, renda, segurança social, educação, para toda população, preservando o ambiente, as características locais e difundindo a idéia de um desenvolvimento territorial integrado e sustentável, onde impere a solidariedade e a justiça social. Conforme afirma Sachs (2002), a intersecção desses conceitos e dimensões possibilita a ascensão 
de estratégias, num esforço conjunto, para a condução e prosperidade das atividades socioeconômicas e das comunidades, bem como, a preparação dos indivíduos e das organizações sociais para enfrentarem os constrangimentos e pressões dos mercados, num circuito de integração que invoque o que Astley (1984) denomina de "estratégia coletiva".

No âmbito da governança territorial observamos, também, o crescimento de inúmeros estudos que buscam integrar aos instrumentais de avaliação econômica dos setores produtivos a avaliação e articulação dos agentes econômicos e os atores sociais envolvidos. No caso de setores tradicionais verificamos grande relevância de estudos sobre as dinâmicas socioculturais locais, principalmente com o intuito de avaliar a existência de um tecido sociocultural capaz de potencializar a introdução de mecanismos da economia social no nível local e a reciprocidade e cooperação apontada por Ostrom (1990). No entanto, não basta analisarmos as questões socioeconômicas isoladas, temos que integrá-las aos entraves de cunho sociopolítico e socioambiental, ou seja, a interação dos conceitos de desenvolvimento territorial sustentável, economia social e governança são imprescindíveis para o avanço da pesquisa no campo do planejamento do desenvolvimento. Dessa forma, necessitamos de estudos empíricos que enfatizem a integração e articulação desses conceitos com o intuito de promover subsídio para as ações de planejamento e gestão territorial.

Assim, consideramos fértil tal análise, pois se as atividades econômicas conseguirem se estruturar privilegiando modos de governança compartilhada entre Estado, mercado e sociedade civil organizada, baseados na consertação e na busca por equilíbrio entre as dimensões do desenvolvimento, menos recorrentes seriam os impactos socioambientais graves. Quanto mais distantes estiverem os agentes econômicos e sociais, mais próximo a um modelo pautado em vantagens comparativas. Isto significa dizer que, quanto mais mecanismo de governança territorial, maiores serão as potencialidades para a construção de modelos de gestão territorial que privilegiem as vantagens diferenciadoras (PECQUEUR, 2006) 7 . A partir dessa reflexão teórica, apre-

\footnotetext{
A noção de vantagens comparativas remete à perspectiva clássica de David Ricardo, no qual os defensores do livre comércio explicavam que a maior eficiência produtiva, derivada da especialização, contribuiria para a elevação do bem-estar social global. Esse fato ocorreria em função de colocar à disposição dos consumidores maiores volumes de bens e serviços, a preços mais convenientes, sendo que a própria concorrência se encarregaria de regular preço e quantidade de mercadorias a serem vendidas. Já a noção de vantagens diferenciadoras está baseada na premissa de que um sistema produtivo local deveria buscar fugir da concorrência global por meio dos recursos e ativos territoriais
} 
Desenvolvimento territorial sustentável em debate: estrutura e organização da pesca artesanal na Grande Florianópolis

sentaremos os principais resultados da pesquisa sobre a pesca artesanal na Grande Florianópolis.

\section{APESCAARTESANAL NA GRANDE FLORIANÓPOLIS: LIMI- TES E POTENCIALIDADES RUMO AO DESENVOLVIMENTO TERRITORIAL SUSTENTÁVEL}

A região da Grande Florianópolis é formada por dois conjuntos de paisagens naturais, as áreas interioranas das encostas da serra, constituídas por montanhas, vales, rios e Mata Atlântica e as áreas litorâneas, constituídas por praias, lagoas, enseadas, dunas e áreas arenosas com sua vegetação típica, além de mata nos morros e áreas mais altas (GOVERNO DO ESTADO DE SANTA CATARINA, 2010). Nesse contexto paisagístico localizam-se 22 municípios $^{8}$. Para fins deste artigo tomamos como base o recorte de municípios da Associação de Municípios da Grande Florianópolis, pois consideramos, num primeiro momento, o recorte das associações de municípios férteis para consecução de trabalhos sobre o DTS.

No que se refere ao povoamento e colonização da região, observamos que ela sofre influência de diferentes fluxos migratórios que povoaram o estado de Santa Catarina. A ocupação do território da Grande Florianópolis deu-se, assim, por povos europeus e seus descendentes, processo que transcorreu ao longo de quatro séculos, no contexto da grande expansão mundial européia (PIAZZA, 1988; PIAZZA, 1983). Além, é claro, de a porção litorânea ser povoada originalmente pelos índios carijós.

No contexto da trajetória de desenvolvimento da região da Grande Florianópolis destacamos que a consolidação da atividade pesqueira ocorreu entre 1940 e 1960. De 1970 a 1990 a pesca passa a obter incentivos, prin-

específicos. A possibilidade de um território apresentar vantagens diferenciadoras pressupõe a existência de um sistema de governança local, de mecanismos de valorização de identidades cultural e da qualidade do patrimônio natural e cultural. Quanto mais intenso for o sentido de pertencimento ao local, maior se torna a probabilidade de que o território e todos que o compõem - empresas e seres humanos - estejam aquém da expectativa de obtenção de vantagens comparativas, modelo constituído por empresas nômades no qual buscam a minimização dos custos de produção (PECQUER, 2004; PECQUEUR, 2006; MENEZES, 2009).

8 Os municípios que compõem a Grande Florianópolis são: Águas Mornas, Alfredo Wagner, Angelina, Anitápolis, Antônio Carlos, Biguaçu, Canelinha, Florianópolis, Garopaba, Governador Celso Ramos, Leoberto Leal, Major Gercino, Nova Trento, Palhoça, Paulo Lopes, Rancho Queimado, Santo Amaro da Imperatriz, São Bonifácio, São João Batista, São José, São Pedro de Alcântara e Tijucas (ASSOCIAÇÃO DE MUNICÍPIOS DA GRANDE FLORIANÓPOLIS, 2010) 
cipalmente com a abertura de mercado e com isso observamos um avanço significativo da pesca industrial. Ao mesmo tempo, verificamos, a partir da década de 1990, o aumento da especulação imobiliária, expansão das cidades e explosão do turismo de massa. Todos esses elementos que compõem a trajetória socioeconômica da região acarretaram, nos últimos anos, uma pressão sobre a atividade da pesca artesanal e os recursos pesqueiros do litoral.

Para compreendermos a trajetória da pesca artesanal na região da Grande Florianópolis necessitamos entender como o setor pesqueiro se consolida como atividade econômica no Brasil, nas últimas décadas. Foi no final da década de 1990 e início dos anos 2000, que a pesca foi considerada prioridade nacional. Na década de 1990, o setor obteve apoio do governo e, em pouco tempo, se conseguiu dobrar a produção de pesca, "que passou a ocupar o segundo lugar entre as carnes (só superado pela bovina), atingindo a produção de um milhão de toneladas/ano e gerando cerca de 300 milhões de dólares em exportação." (TIMM, 2002, p. 20). De acordo com o autor supracitado, nesse mesmo período o cooperativismo pesqueiro também foi priorizado e diversas cooperativas emergiram, lideradas pela Associação Nacional das Cooperativas de Pesca. Nos períodos posteriores, o Governo ao enfatizar a preservação ambiental e a conservação dos recursos naturais, bem como a transição econômica do país, ocasionou uma queda no incentivo da pesca, regredindo a produção em cerca de 700 mil toneladas (TIMM, 2002). Assim como muitas empresas de pesca não conseguiram sobreviver a essa fase, também a maioria das cooperativas acabou deixando o mercado.

Após esse período de estagnação, com a retomada de incentivo pelo governo brasileiro, na última década, a prioridade para o desenvolvimento da pesca e da aqüicultura refletiu-se em um aumento da produção pesqueira e o incremento do cultivo de peixes. Embora tenhamos observado o incremento na produção na última década, em geral direcionados para a indústria da pesca, há inúmeras dificuldades a serem enfrentadas pela pesca artesanal no Brasil (CABRAL, 2008). Dentre esses problemas está a falta de confiança nas estatísticas de pesca, a competição pelo peixe com a frota industrial, a especulação imobiliária nas zonas costeiras, o turismo de massa e as dificuldades de inserção mercadológica.

No que se refere aos dados da dinâmica da pesca artesanal em relação as demais modalidades de pesca em Santa Catarina, comparativamente a Região Sul e o Brasil, conforme Ibama (2010) temos: 
Desenvolvimento territorial sustentável em debate: estrutura e organização da pesca artesanal na Grande Florianópolis

\begin{tabular}{|l|l|c|l|c|l|c|l|}
\hline \multirow{2}{*}{ Regiões/UF } & \multicolumn{4}{|l|}{ Pesca Extrativa } & \multicolumn{2}{l|}{ Aqüicultura } & Total (t) \\
\cline { 2 - 8 } & Industrial & $\%$ & Artesanal & $\%$ & Total & $\%$ & \\
\hline Brasil & $277.364,5$ & 25,9 & $505.812,0$ & 47,2 & $289.049,5$ & 27,0 & $1.072 .226,0$ \\
\hline Região Sul & $151.154,0$ & 59,3 & $25.573,5$ & 10,0 & $78.350,0$ & 30,7 & $255.080,5$ \\
\hline Santa Catarina & $138.162,5$ & 74,9 & $11.536,0$ & 6,3 & $34.795,0$ & 18,9 & $184.493,5$ \\
\hline
\end{tabular}

Quadro 1: Dados da pesca industrial, artesanal e aqüicultura de 2007 (em toneladas e em percentual)

Fonte: IBAMA (2010)

Conforme o Quadro 1 a pesca artesanal no Brasil é mais produtiva que as demais modalidades de pesca, representando 47,2\% do total. Já em Santa Catarina esse percentual reduz-se significativamente, representando apenas 6,3\%. Essa discrepância nas estatísticas brasileira e catarinense dáse em função da região sul do Brasil ser mais rica em termos de recursos pesqueiros. Conforme entrevistado do Ibama-Cepsul, tal situação é fruto de uma corrente fria que provém do Oceâno Pacífico. Embora esses dados do IBAMA (2010), para Santa Catarina, demonstrarem maior capacidade da pesca industrial do que da artesanal, é importante frisar que, a pesca artesanal tem significativa importância para o Estado, onde existiam cerca de 25 mil pescadores artesanais em atividade em 2008 (SEVERO, 2008). Além dos problemas citados anteriormente, existem aqueles relativos à dificuldade de manutenção das colônias de pescadores em função da sazonalidade e dos problemas da concorrência com a pesca industrial, da poluição e degradação do meio ambiente marinho, dentre outros (SEVERO, 2008).

Dentre os problemas da pesca artesanal está a convivência, especialmente, no sul do país com a industrial. Essa convivência decorre de vontade política para a estruturação de estratégias mais sustentáveis do ponto de vista social, econômico e ambiental, principalmente da pesca artesanal. É fato que a pesca artesanal sobrevive paralelamente, sendo destinada principalmente à subsistência de pequenas colônias de pescadores em regiões ribeirinhas e litorâneas, que utilizam redes de pequeno porte, espinhéis, tarrafas e redes de espera e que a industrial vale-se de uma cadeia produtiva bem mais estruturada e articulada internacionalmente. Todavia, é preciso rever papéis e políticas para a convivência harmônica e equilibrada dessas duas atividades econômicas, principalmente em função da pesca artesanal agregar, além do trabalho e renda gerado, um componente cultural rico e que deverá ser 
preservado. Para aprofundar esse debate, na seção seguinte discutiremos as principais características da pesca artesanal da Grande Florianópolis, para, então, apresentarmos os seus arranjos institucionais.

\subsection{Características da pesca artesanal na Grande Florianópolis}

Para compreender melhor aspectos importantes da pesca artesanal é preciso reconhecer que essa modalidade de pesca se realiza pelo trabalho manual do pescador. Nela a participação do homem em todas as etapas e manipulação dos implementos e do produto é total, ou quase total. Geralmente essa atividade está baseada em conhecimentos transmitidos ao pescador por seus ancestrais, pelos mais velhos da comunidade, ou pelo conhecimento adquirido através da interação com os companheiros do ofício (MENEZES; CAVICHIOLI, 2005).

A cadeia produtiva da pesca artesanal pode ser representada pelas atividades sintetizadas e ilustradas pela Figura 1 a seguir:

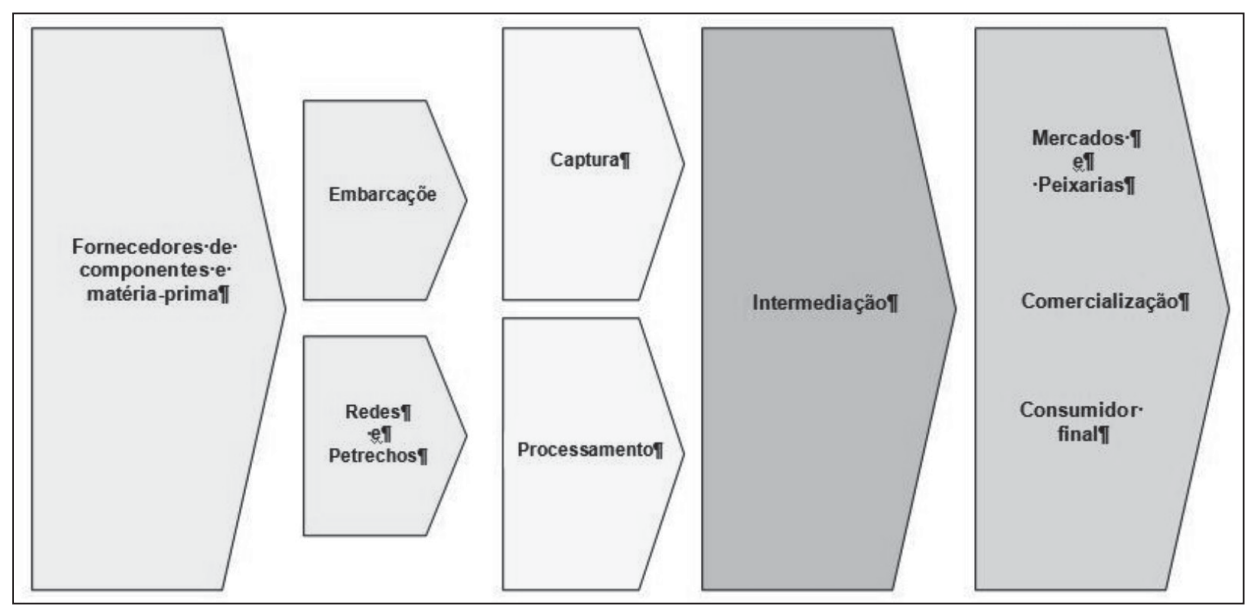

Figura 1: Cadeia produtiva da pesca artesanal Fonte: Elaborado pela autora

A cadeia produtiva da pesca artesanal, conforme verificamos pela ilustração da figura 1, se estrutura sobre as bases: 
Desenvolvimento territorial sustentável em debate: estrutura e organização da pesca artesanal na Grande Florianópolis

i) fornecedores: das embarcações e dos petrechos de pesca. No âmbito dos fornecedores de insumos, observamos poucas dificuldades, nas falas dos entrevistados, já que o Ministério da Pesca e Aqüicultura - MPA vem suprindo grande parte das demandas por financiamento dessa fase da cadeia produtiva, tendo suporte técnico da Epagri. Os programas do Governo Federal Pronaf-pesca, Revitaliza, Subsídio do óleo diesel, fábrica de gelo, entre outros programas têm, relativamente, sido acessado pelos pescadores da região pesquisada. Conforme a opinião quase que unânime dos entrevistados a criação do MPA alavancou o fomento dessa fase da cadeia produtiva, embora ainda haja inúmeros entraves de cunho burocrático.

ii) captura e processamento: fase cuja a atividade humana é imprescindível. No quadro do perfil dos pescadores dos municípios da Grande Florianópolis pesquisados ${ }^{9}$, observamos, na sua maioria, que é composto por homens, embora em Governador Celso Ramos as mulheres tenham uma presença significativa, especialmente na fase de processamento do pescado. A média de idade é de 30 a 60 anos, com baixo grau de escolaridade e em sua maioria estão vinculados institucionalmente às Colônias de Pesca ou ao Sindicato. A formação da mão de obra vinculada a esta fase da cadeia produtiva ocorre pela transmissão de conhecimento (de pai para filho) e através de cursos oferecidos pela capitania dos portos. A captura e processamento são, em geral, realizados pelo próprio pescador e seus familiares.

iii) intermediação e comercialização: fase cuja atividade se restringe ao ato de compra e venda do pescado. Do ponto de vista das espécies e do mercado percebemos que na pesca artesanal ocorre à captura de diferentes espécies quando comparado à pesca industrial. Os produtos da pesca artesanal tendem a ter maior preço de comercialização, pois a qualidade do que é pescado artesanalmente é elevado, em função de o abate ser relativamente recente. Todavia, essa fase da cadeia produtiva apresenta inúmeros obstáculos. Nessa fase da cadeia produtiva, pós captura, a figura mais importante é a do intermediário que também aparece em alguns casos na facilitação do acesso aos outros insumos

Governador Celso Ramos e Florianópolis 
como óleo diesel e petrechos de pesca. Nesse caso, o intermediário age como financiador da atividade. Tal fato acarreta uma relação de dependência entre pescador e intermediário, cujo pescador fica obrigado a descarregar e vender sua produção com baixo poder de "barganha". Porém, existem os pescadores que por não estarem atrelados ao intermediário-comprador, efetuam a comercialização diretamente ao consumidor final (moradores, turistas, restaurantes, etc.), obtendo maiores vantagens e maior poder de barganha.

É, portanto, o processo de comercialização uma fase da cadeia produtiva enigmática para a governança atual da pesca artesanal. Sem desconsiderar a importância da divisão do trabalho que acontece dentro das comunidades e sem, portanto, desconsiderar a relevância social da atividade de intermediação, faremos uma breve sistematização dessa etapa da cadeia produtiva para melhor compreender as potencialidades e os limites impostos por essa atividade:

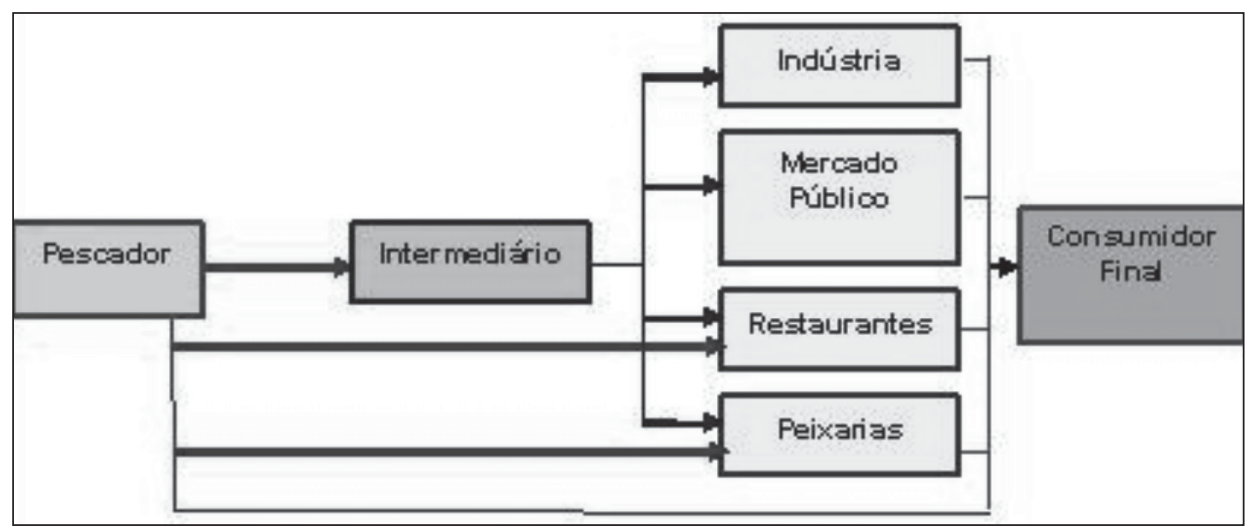

Figura 2: Processo de comercialização da produção pesqueira artesanal Fonte: Elaboração da autora.

O processo de comercialização da pesca artesanal é, conforme entrevistado representante da Prefeitura de Governador Celso Ramos, proveniente do nascedoura da própria pesca da região. Observamos uma divisão do trabalho dentro das comunidades, em que existem aqueles especializados na captura e todas as atividades que estão vinculadas a ela, e outros especializados na comercialização e consequentemente nas atividades relacionadas à ela. 
Desenvolvimento territorial sustentável em debate: estrutura e organização da pesca artesanal na Grande Florianópolis

Os agentes compradores da produção pesqueira artesanal da região estão elencados nos cinco atores ilustrados na Figura 2. Há aquela situação em que o pescador tem uma relação direta com o consumidor final, em muitos casos a venda ou doação acontece logo após a pesca, ainda na beira da praia. Outra em que o pescador tem algum vínculo de parentesco ou amizade com proprietários de restaurantes e peixarias, como é o caso da Costa da Lagoa, em que muitos pescadores capturam espécies para suprir seus próprios restaurantes. Uma terceira modalidade é aquela em que o pescador repassa a sua produção diretamente ao intermediário e este, por sua vez, comercializa a produção junto aos restaurante, peixarias, entre outros consumidores ou, ainda, repassa a produção para a indústria da pesca. Porém, é mais comum que a produção dos pescadores artesanais alimentem o comércio local. Por isso, é tão importante compreender as nuances das relações existentes entre esses agentes locais.

Os entraves descritos em inúmeros documentos que retratam a realidade da pesca artesanal no que tange ao seu processo de comercialização são relativamente importantes a nosso ver. Porém, há necessidade de aprofundamento na divisão do trabalho existente dentro das comunidades para, então, perceber quais estratégias alternativas poderiam ser veículadas em prol de maior dinamização da atividade. As experiências acompanhadas pelo SOLTEC (2009), se aproximam da necessidade de constituição de empreendimentos sociais que integrem a família do pescador no processamento e comercialização na região de Macaé - Rio de Janeiro. Contudo, é uma realidade diversa da de Santa Catarina e da Grande Florianópolis.

A impressão da realidade catarinense demonstra que ações para descarcterizar esse processo de comercialização sem a integração efetiva dos intermediários, ou seja, de uma atividade reconhecida pelos pescadores, parece, a nosso ver, não surtir efeito positivo. Por isso, há necessidade de constituirmos estudos que possam demonstrar a receptividade local quanto à constituição de unidades de beneficiamento coletivas, que aumentam o valor agregado do pescado e que ainda integre todos da comunidade, incluindo nesse conjunto de atores os intermediários. Assim, a seção a seguir buscará analisar com maior profundidade as características dos arranjos institucionais da pesca artesanal da Grande Florianópolis. 
Elaine Cristina de Oliveira Menezes • Maurício Serva

\subsection{Arranjos institucionais da pesca artesanal na Grande Florianópolis: contribuições para se pensar alternativas mais sustentáveis para a pesca artesanal}

No âmbito das instituições de apoio e órgãos públicos ligados ao segmento artesanal, identificamos que a governança pública federal é permeada por vários ministérios, mas com a coordenação a cargo do Ministério da Pesca e Aqüicultura (MPA) no que tange ao fomento e organização e do Ministério do Meio Ambiente (MMA), no que se refere a fiscalização e regulamentação. A coordenação de algumas ações é mediada, também, pela Marinha do Brasil e pelo Ministério do Desenvolvimento Agrário. Embora o MPA seja o responsável por ações relativas à pesca, o MMA regula as leis que compõem o setor. Nesse sentido, observamos que o primeiro realiza ações de fomento ao setor, denotando um cunho desenvolvimentista. Já o segundo, restringe o âmbito de acesso à pesca, pois possui um cunho mais conservacionista.

A partir das entrevistas constatamos que as ações dos dois ministérios ainda não são sincronizadas e isso se reflete na operacionalização da pesca na região em estudo e, também, na implementação dos programas de governo para o setor. Isto é, o fato dos ministérios serem regidos por objetivos diferentes, causa um entrave na própria gestão pública do setor e que se reflete em ações confusas para o pescador. É possível que esse desajuste ainda seja reflexo da incipiência do Ministério da Pesca e Aquicultura. No entanto, a gestão pública tem o dever de colocar em primeiro plano o interesse público, acima das questões ideológicas, político-partidárias, entre outras. No âmbito estadual e local a gestão pública da pesca ainda é bastante incipiente, limitando-se apenas a uma secretaria de agricultura e pesca no estado e à Epagri e no nível municipal as secretaria de agricultura e pesca.

Através do levantamento das organizações que operam no segmento da pesca artesanal na região é possível, também, perceber que há uma rede institucional formal de base não-governamental, a das Colônias de Pesca. As colônias de pesca já existem, conforme Presidente da Federação das Colônias de Santa Catarina, a 200 anos. A primeira Colônia foi fundada em Porto Belo. Porém, institucionalmente, as Colônias têm um avanço a partir de 1967 e o seu sistema se divide em: i) colônia, representação no âmbito municipal; ii) federação, representação no âmbito estadual; e iii) confede- 
Desenvolvimento territorial sustentável em debate: estrutura e organização da pesca artesanal na Grande Florianópolis

ração, representação no âmbito federal. Segundo Presidente da Federação das Colônias de Santa Catarina são as colônias entidades representantes dos pescadores artesanais. A Lei da Pesca de 29 de junho de 2009 e a nova Lei das Colônias de 13 de junho de 2008 trouxeram inúmeros avanços para a consolidação do setor, inclusive sendo elas reconhecidas como órgãos de classe dos trabalhadores do setor artesanal da pesca, com forma e natureza jurídica próprias, obedecendo ao princípio da livre organização previsto no artigo 8 da Constituição Federal (LEI N. 11.699 de 2009).

No entanto, para alguns pescadores, essa entidade de classe, tão antiga e que deveria representá-los, está permeada pela cultura política brasileira, cujo clientelismo e paternalismo predominam. A fala de um pescador que trabalha na pesca em Florianópolis a mais de cinqüenta anos corrobora com essa percepção: "Comecei a pagar a colônia antes de 1963 e nada fazem (Pescador artesanal de Florianópolis).” No entanto, em função dessas organizações serem bastante antigas e envolverem relações familiares, de vizinhança e de amizade são, ainda, entidades que têm certa representatividade perante o pescador.

Já o Sindicato dos Pescadores do Estado de Santa Catarina, outra entidade de classe, foi criado em 1964, recebeu sua carta sindical em 1965, declarado de utilidade pública pela lei estadual n ${ }^{\circ} 9.297$ de 21 de outubro de 1993. De acordo com a opinião de alguns dos entrevistados, essa entidade faz concorrência às atividades da colônia. O seu surgimento e organização nos últimos anos trouxe rivalidade entre as Colônias e o Sindicato, o que acabou dividindo, muito mais do que unindo a categoria. A impressão diante da pesquisa de campo é de que são as Colônias as entidades que possuem maior representatividade junto dos pescadores artesanais. Embora, algumas lideranças não sejam legítimas, em função da predominância das questões político-partidárias, a instituição Colônia possui representatividade como órgão de classe para o pescador. Algumas críticas direcionadas ao sindicato e à algumas colônias estão no fato dessas organizações disponibilizarem condições para que pessoas que não exercem a profissão de pescador possam vir a ser pescadores artesanais profissionais, acabando por usufruir do defeso sem o seu direito moral.

Além dessas organizações, no quadro da governança não-governamental, observamos a existência de associações e de cooperativas de pescadores 
na Grande Florianópolis. Porém, observamos que elas ainda têm pouca representatividade. Essas organizações na Grande Florianópolis totalizam 31 (ligadas à pesca e à aqüicultura), 15 associações/cooperativas de pescadores são de Florianópolis e duas de Governador Celso Ramos. As associações/ cooperativas mais atuantes são aquelas que coordenam o transporte de turistas, atividade alternativa e complementar à pesca que já é realizada, principalmente, no município de Florianópolis e, aquelas relativas à maricultura. Muitos pescadores já sentem que há necessidades de maior articulação e envolvimento da categoria. Todavia, a cultura do pescador artesanal, conforme a opinião da maioria dos entrevistados é, ainda, muito "individualista".

O fato de usufruírem de um recurso de uso comum, sem terem a propriedade privada, é tido como uma das causas dessa dificuldade de consenso e confiança entre seus pares. Nas falas dos próprios pescadores observamos que eles estão dispostos a ajuda mútua na dificuldade, interagem nas festas e eventos comunitários, mas ainda não estão preparados para a organização conjunta de ações em prol do setor. Essa talvez seja a causa de muitas estatísticas de pesca artesanal ser questionável, em função do pescador não informar exatamente qual a quantidade pescada, por desconfiança e medo.

Assim, percebemos que as iniciativas voltadas para a coordenação da dinâmica inter-organizacional permanece nas mãos de poucas pessoas, especialmente no que refere às liderança comunitárias. Esse fato dá-se em função, por um lado, da falta de interesse dos pescadores de participação da gestão setorial e territorial, e, por outro lado, das relações político-partidárias existentes no âmago dessas organizações. Dessa forma, a pesquisa reforçou a impressão de que ainda há muito que fazer em prol da qualidade do meio ambiente e da organização do setor. $\mathrm{O}$ enfoque econômico clássico das instituições, intervenções e administrações públicas é ainda predominante, mostrando-se insuficiente para um enfrentamento consequente dos problemas de gestão ambiental integrada e participativa no longo prazo (GODARD, 2000).

Por outro lado, existem, ainda que embrionariamente, relações de proximidade e reciprocidade entre os pescadores. Porém, quando confrontados com o econômico, tendem a ser "individualistas", o que nos parece ambíguo, pois como argumenta Ostrom (1990; 2010), os ganhos coletivos são maiores que os individuais e tal fato ainda não foi considerado pelo conjunto 
Desenvolvimento territorial sustentável em debate: estrutura e organização da pesca artesanal na Grande Florianópolis

dos pescadores. Portanto, a nosso ver, a grande carência dos pescadores artesanais na atualidade é a de formação para a economia social e para uma nova forma de usufruírem de um recurso de uso comum num contexto de degradação e escassez dos estoques pesqueiros.

Todos os problemas de cunho institucional, social, ambiental e mercadológico está permeado pela percepção que a pesca artesanal usufrui de um recurso de uso comum e que a questão da reprodução dos estoques afeta diretamente a todos, assim como a reprodução da atividade artesanal. Assim, a nosso ver, a gestão pública deveria privilegiar políticas de preservação da pesca artesanal que alimenta o mercado regional e que mobiliza a economia local. Além disso, muitas técnicas de pesca já vem sendo condenável em muitos países, como por exemplo o arrasto. Nesse sentido, à gestão pública brasileira caberia o esforço de reconhecer quais são as técnicas menos agressivas para a reprodução dos estoques. À gestão pública caberia, também, garantir a transição dos pescadores artesanais para essas inovações, fomentando e financiando a aquisição de equipamentos mais adaptados, bem como promovendo a formação dos pescadores para essa nova realidade. A nosso ver, o grande entrave da pesca artesanal na atualidade é de cunho informacional.

Concluímos que a governança da pesca artesanal na Grande Florianópolis, mais especificamente em Florianópolis e Governador Celso Ramos, possui questões emblemáticas semelhantes e divergentes. É possível perceber que o fato de Florianópolis ser a capital do Estado e ser sede de uma economia baseada no turismo e no serviço, os pescadores artesanais já vem encontrando alternativas socioeconômicas para sua subsistência e de sua família, denotando a multifuncionalidade familiar e a saída de inúmeras famílias e pescadores da atividade artesanal. Em Governador Celso Ramos percebemos que a economia local é muito mais depende da pesca do que a de Florianópolis. Nesse sentido, o impacto da governança pública e setorial sobre a qualidade territorial é bastante significativa. Ambos os municípios sofrem com o governança setorial em virtude das organizações responsáveis pelo setor ainda serem pouco articuladas e atuarem de forma fragmentada. Portanto, verificamos que os arranjos institucionais da pesca artesanal ainda não conseguiram modelar modos de regulação baseado na consertação e na cooperação. 
Em síntese, constatamos um déficit de credibilidade da rede de instituições locais, regionais e nacionais junto aos pescadores artesanais que vem sendo revertido pela presença do Ministério da Pesca e Aquicultura. As potencialidades da pesca artesanal estão no fortalecimento das redes comunitárias já existentes e os seus limites estão vinculados à cultura política brasileira e a tendência à escassez dos estoques pesqueiros. A governança desse setor reforça a idéia de que a pesca artesanal está desprovida de investimento em aprendizagem coletiva e em informação, o que a torna ainda mais frágil no contexto econômico atual de pressões econômicas globais.

\section{CONSIDERAÇÕES FINAIS}

Diante do contexto da pesca artesanal que sofre pressões da indústria pesqueira, especulação imobiliária, turismo de massa e desarticulação interna do setor, os pescadores artesanais sofrem com o efeito da perda de renda, do desemprego e da exclusão social. Nesse sentido, compreender a governança da pesca e os mecanismos da economia social e plural emergem como uma das alternativas para os problemas atuais que envolvem a pesca artesanal e a sustentabilidade territorial e socioambiental.

Percebemos deficiências na governança local, pela presença de uma cultura política clientelista e paternalista, permeada pelo desinteresse dos próprios pescadores artesanais. Do ponto de vista da governança pública observamos grande fragmentação das ações em prol da pesca artesanal, acarrentando conflitos e desorganização no setor. Há, embrionáriamente instituições de economia social que poderiam resgatar ação coletiva das comunidades e reestruturarem as relações dos atores locais. Porém, faz-se necessário investimento, não só em equipamentos e petrechos de pesca, mas em aprendizagem coletiva por parte da gestão pública.

Assim, verificamos que o processo de constituição e as macrodiretrizes das organizações que compõem o segmento da pesca artesanal não estão contribuindo para o desenvolvimento de ações em prol das comunidades e do território. Dessa forma, as políticas públicas deveriam ser orientadas no sentido do fortalecimento da formação de redes solidárias, pois são essas redes que poderão ajustar as políticas públicas para o setor, bem como definir melhores estratégias para enfrentamento da crise da pesca artesanal em Santa Catarina e na região da Grande Florianópolis. 
Desenvolvimento territorial sustentável em debate: estrutura e organização da pesca artesanal na Grande Florianópolis

No que tange à sustentabilidade socioambiental consideramos que o pescador artesanal é, em certa medida, consciente da sua relação com a natureza e com os problemas que ele pode causar com a sobrepesca. Porém, a falta de formação e de articulação do conhecimento ecológico local, ao conhecimento científico, a falta de fiscalização efetiva (pela comunidade e pela gestão pública) acarreta a perda dos estoques pesqueiros e o desajuste do uso do período do defeso. Sem contar que o turismo de massa e a própria indústria da pesca promovem a degradação das regiões costeiras.

Não podemos negar que a pesca artesanal além de proporcionar maior variedade de espécies na mesa do consumidor final, também promove a atividade extrativa mais sustentável em termos sociais e ambientais. Todavia, é preciso rever papéis e políticas para a convivência harmônica e equilibrada das atividades econômicas, principalmente em função da pesca artesanal agregar, além do trabalho e renda gerados, um componente cultural rico, da cultura caiçara e açoriana e que deverá ser preservada. Por isso, o presente estudo demonstra a necessidade de replicação de estudos sobre a pesca artesanal e seus arranjos institucionais, para que possamos pensar estratégias alternativas mais compatíveis com o desenvolvimento territorial sustentável. Além disso, consideramos férteis estudos que demonstrem a viabilidade de proliferação de organizações de economia social para alavancagem da pesca artesanal e de atividades econômicas menos degradantes do ponto de vista socioambiental nos municípios em questão.

\title{
DISCUSSING SUSTAINABLE TERRITORIAL DEVELOPMENT: STRUCTURE AND ORGANIZATION OF SMALL-SCALE FISH- ING IN GREATER FLORIANÓPOLIS
}

\begin{abstract}
This research aims to identify the main characteristics of artisanal fisheries in the Great Florianópolis region, its structure and organization, seeking to assess its potential in promoting local initiatives on more sustainable development. This study has the guiding concept of Sustainable Territorial Development, reinforced by definition of Governance, Plural and Social Economy, whose premises are oriented by solidarity and cooperation,
\end{abstract}


prioritizing people and environment more than capital in the distribution of its benefits. Regarding the methodology, this is an exploratory-descriptive research, using a predominantly qualitative approach and semi-structured interviews. Results demonstrate that, despite the difficulties, fishing communities are looking for alternatives, and mainly, they are seeking to strengthen the local governance of the sector. However, it is possible to realize some governance limits, especially in relation to the presence of a paternalistic and privileged political culture. From the standpoint of public governance, it is possible to observe a big fragmentation of actions in favor of artisanal fisheries, causing the conflicts and disorganization of its actions. Investment is necessary from the public management not only in equipments and fishing gears, but also in collective learning.

Keywords: Sustainable territorial development. Governance. Artisanal fisheries.

JEL Classification: Q56.

\section{REFERÊNCIAS}

ANDION, Maria Carolina e SERVA. A Economia Social no Brasil: panorama de um campo em transformação. In: URALDE, José Maria Pérez (coord.). La Economía Social em Iberoamérica: um acercamiento a su realidad. Valencia: FUNDIBES, 2005.

ASTLEY, W. Graham. Toward na Appreciation of Collective Strategy. Academy of Management Review, v. 9, n. 3, 1984.

CABRAL, Daniel Henrique Severino de Lima Bezerra. Pesca artesanal brasileira: rumo ao cooperativismo. Disponível em: $<$ http://www.gci.inf. br/edicoes_anteriores/04/artigoi_opiniao_01.pdf >.Acesso em: 15 abr 2008.

GAUDIN, Jean-Pierre. Pouquoi la gouvernance? Paris: Presses de Sciences Po, 2002. 
Desenvolvimento territorial sustentável em debate: estrutura e organização da pesca artesanal na Grande Florianópolis

GODARD, Olivier. A gestão integrada dos recursos naturais e do meio ambiente : conceitos, instituições e desafios de legitimação. In: VIEIRA, Paulo Freire \& WEBER, Jacques (Orgs.). Gestão de recursos naturais renováveis e desenvolvimento. Novos desafios para as ciências ambientais. São Paulo: Cortez, 2000, p. 201-266.

GOVERNO DO ESTADO DE SANTA CATARINA. Caracterização geral da Grande Florianópolis. Disponível em: <soo.sdr.sc.gov.br/index. php?option=com_docman\&task $>$. Acesso em: 01 mar 2010.

IBAMA. Estatística da pesca 2007. Disponível em: <http://www.ibama. gov.br/recursos-pesqueiros/wp-content/files/estatistica_2007.pdf $>$. Acesso em: 01 mar 2010.

IRION, J. E. Cooperativismo e economia social. São Paulo : STS, 1997.

LÉVESQUE, Benoît. Contribuição da nova sociologia econômica para repensar a economia no sentido do desenvolvimento sustentável. RAE, v. 47, n. 2, abr./jun. 2007.

LISBOA, Armando de Melo. Mercado e economia solidária. In: SHERER -WARREN, Ilse; FERREIRA, José Maria Carvalho (Org.). Transformações sociais e dilemas da globalização: um diálogo Brasil/Portugal. São Paulo: Cortez, 2002.

MENEZES, Elaine Cristina de Oliveira; CAVICHIOLI, Marcelo. As estratégias de sobrevivência das comunidades pesqueiras do Vale do Itajaí. Itajaí: [s.n.], 2005. Mimeo (Relatório de pesquisa Artigo 170).

ONETO, Juan José Sarachu. La importancia de las cooperativas y la Economía Social como instrumentos de inclusión y cohesión social. El caso de Uruguay. In: URALDE, José Maria Pérez (coord.). La Economía Social em Iberoamérica: um acercamiento a su realidad. Valencia: FUNDIBES, 2005.

OSTROM, Elinor. Governing the commons: the evolution of institutions for collective action. New York: Cmbridge University Press, 1990. 
OSTROM, Elinor. Gouvernance des biens communs: pour une nouvelle approche des ressources naturelles. Paris : De Boeck, 2010.

OURIQUES, Helton Ricardo. Turismo em Santa Catarina: notas sobre o mercado de trabalho do setor. Chapecó: UNOCHAPECÓ. Cadernos de Economia. Ano 11, n. 21, jul/dez 2007.

PECQUEUR, Bernard. A guinada territorial da economia global. Florianópolis: [s.n.], 2005. (Palestra proferida junto ao Curso de Graduação e Programa de Pós-Graduação em Agronomia, CCA). UFSC, Florianópolis, 2005.

A guinada territorial da economia global. Eisforia: desenvolvimento territorial sustentável: conceitos, experiências e desafios teóricometodológicos. Florianópolis: PPGAGR, v. 4, n. especial, dez. 2006.

PIAZZA, Walter F. A colonização de Santa Catarina. Florianópolis: Lunardelli, 1988.

delli, 1983.

Santa Catarina: sua História. Florianópolis: UFSC/Lunar-

RAIS. Dados do número de empresas e emprego divisão CNAE 2000. Disponível em: http://sgt.caged.gov.br/XOLAPW.dll/fsmMain?C=false\&$\mathrm{D}=$ false. Acesso em: dez 2010.

RENASCIMENTO NO SETOR PESQUEIRO. Revista SINDIPI, n. 5, 2003.

SABOURIN, Eric. Manejo dos recursos comuns e reciprocidade: os aportes de Elinor Ostrom ao Debate. Sustentabilidade em Debate. Brasília: Universidade Federal de Brasília, v. 1, n. 2, dez. 2010.

SACHS, Ignacy. Desenvolvimento humano, trabalho decente e o futuro dos empreendedores de pequeno porte no Brasil. Brasília: SEBRAE, 2002. 
Desenvolvimento territorial sustentável em debate: estrutura e organização da pesca artesanal na Grande Florianópolis

Ecodesenvolvimento: crescer sem destruir. São Paulo: Vértice, 1986.

Ecodesenvolvimento: 1972-1992. In: Agricultura e Meio Ambiente. Rio de Janeiro: Universidade Federal do Rio de Janeiro. Ano 1, n. 1, 1992.

Estratégias de transição para o século XXI: desenvolvimento e meio ambiente. São Paulo: Studio Nobel e FUNDAP, 1993.

Rumo à ecossocioeconomia: teoria e prática do desenvolvimento. São Paulo: Cortez, 2007.

SANTOS, Maria João. Processos de modernização empresarial: o papel das redes locais. In: SHERER-WARREN, Ilse; FERREIRA, José Maria Carvalho (Org.). Transformações sociais e dilemas da globalização: um diálogo Brasil/Portugal. São Paulo: Cortez, 2002.

SCHIMIDT, Derli; PERIUS, Vergílio. Cooperativismo - cooperativa. In: CATTANI, Antonio David (org.). A outra economia. Porto Alegre: Veraz Editores, 2003.

SEVERO, Cristiane Marques. Pesca artesanal em Santa Catarina: evolução e diferenciação dos pescadores da Praia da Pinheira. Porto Alegre, 2008. 135 f. (Dissertação de Mestrado) - Programa de Pós-Graduação em Desenvolvimento Rural. Programa Interdisciplinar em Ciências Humanas), UFRGS. 2008.

SINGER, Paul. A economia solidária como alternativa no (e ao) capitalismo. Unitrabalho Informa. Outubro/1998.

SOLTEC. Relatório analítico da pesquisa ação na cadeia produtiva da pesca PAPESCA/UFRJ. Rio de Janeiro: s.n. 2009.

TIMM, José Ubirajara. Cooperativismo pesqueiro. Pesca e mar. Rio de Janeiro, n.77, p. 20, jan./fev. 2002. 
TONNEAU, Jean Philuppe. Desenvolvimento rural sustentável: novo paradigma ou velhas questões. Florianópolis: [s.n.], [200-]. (mimeo).

TRIVIÑOS, Augusto. Introdução à pesquisa em ciências sociais. São Paulo: Atlas, 1987.

VIEIRA, Paulo Freire. Rumo ao desenvolvimento territorial sustentável: esboço de roteiro metodológico participativo. Eisforia: desenvolvimento territorial sustentável: conceitos, experiências e desafios teórico-metodológicos. Florianópolis, v. 4, n. especial, dez. 2006.

. e CAZELLA, Ademir Antônio (org). Desenvolvimento ter-

ritorial sustentável: diagnóstico de potencialidades e obstáculos em zonas rurais dos estados da Paraíba e Santa Catarina. Florianópolis: [s.n.], 2004. (Modelo de análise referente ao projeto de pesquisa - mimeo). 